\title{
Orta Sakarya Vadisi Akarsu Seki Sistemlerinin Morfometrik ve Sedimantolojik Özellikleri (İnhisar-Gemiciköy Arası, Bilecik)
}

\author{
Morphometric and Sedimentological Features of Terrace Systems in the Middle Sakarya \\ Valley (Inhisar-Gemiciköy, Bilecik)
}

\author{
Ebubekir KARAKOCA ${ }^{1} \mathbb{1}$, Levent $\mathrm{UNCU}^{1} \oplus$
}

${ }^{1}$ Bilecik Şeyh Edebali Üniversitesi, Fen Edebiyat Fakültesi, Coğrafya Bölümü, Bilecik, Türkiye

ORCID: E.K. 0000-0002-6454-2082; L.U. 0000-0002-3908-1157

\begin{abstract}
öz
Kuzeybatı Anadolu'nun en büyük akarsuyu olan Sakarya Nehri, orta çı̆̆ırında “Orta Sakarya Platoları” olarak bilinen geniş bir sahanın sularını akaçlamaktadır. Bu saha da Sakarya Nehri vadisi boyunca, bölgenin tektonik ve jeomorfolojik gelişiminin ortaya konulabilmesi açısından son derece önemli olan boğazlar ve seki sistemlerinin varlığı dikkati çekmektedir. Bu çalışmanın amacı, Sakarya Nehri vadisinin Bilecik iline bağlı İnhisar ve Gemiciköy yerleşmeleri arasında kalan kesiminde gözlenen seki sistemlerinin morfometrik ve sedimantolojik özelliklerini ortaya koymaktır. Üst Pliyosen'den itibaren bölgeye yerleşen Sakarya Nehri bir yandan Orta Sakarya Platolarında açmış olduğu boğazları derinleştirirken diğer yandan Kuvaterner sırasındaki iklim değişmeleri, Karadeniz'deki kaide seviyesi oynamaları ve süregelen bölgesel/lokal tektonik hareketlerin kontrolü altında vadisi boyunca birkaç basamak halinde izlenebilen seki sistemlerini geliştirmiş̧ir. Çalışma kapsamında, Sakarya Nehri'nin vadi tabanından itibaren, Gemiciköy çevresinde iki (+19 m ve $+11 \mathrm{~m}$ yükseklikte), Hamitabat köyü çevresinde üç (+36 m, +24 m ve +12 m yükseklikte), Yakacık köyü çevresinde ise dört (+52 m, +34 m, +18 m ve +10 m yükseklikte) seviye halinde seki basamakları tespit edilmiştir. Sakarya Nehri'nin vadisi boyunca düzensiz bir dağılış gösteren bu seki basamaklarının yüksekte bulunanları yarı yuvarlanmış-yuvarlanmış iri çakıllardan, alçakta olanları ise az yuvarlanmış küçük çakıllar ve ince taneli taşkın ovası sedimanlarından oluşmaktadır.
\end{abstract}

Anahtar kelimeler: Sakarya Nehri, Flüvyal Jeomorfoloji, Akarsu Sekisi

\section{ABSTRACT}

Sakarya River, which is the largest river in northwest Anatolia, drains waters from a large area known as the Middle Sakarya Plateau. The most striking geomorphological features of the Sakarya River, and its tributaries in this area, are the joining gorges which connect the basins and terrace systems together. This study aims to reveal the morphometric and sedimentological features of the terrace systems in the area between the Sakarya River, the Inhisar, and the Gemiciköy settlements. The Sakarya River, which has settled in the region from the Upper Pliocene, has formed terrace systems that can be monitored in several steps throughout the valley. They are monitored under the control of the climatic changes during the Quaternary, the sea level changes in the Black Sea, and the cyclical regional/local tectonic movements. Multiple terraces determined in this study area including the following. Starting from the valley floor of the Sakarya River, two terraces ( $+19 \mathrm{~m}$ and $+11 \mathrm{~m}$ height) are determined around Gemiciköy, three terraces ( $+36 \mathrm{~m}$, $+24 \mathrm{~m}$ and $+12 \mathrm{~m}$ height) are determined around Hamitabat village, and four terraces ( $+52 \mathrm{~m},+34 \mathrm{~m},+18 \mathrm{~m}$ and $+10 \mathrm{~m}$ height) are determined in Yakacık village. These terrace formations, which are distributed irregularly along the valley of the Sakarya River, are mostly semi-rounded from large gravel at the high elevations, and at the lower elevations, terrace formations are made of small gravel and floodplain sediments.

Keywords: Sakarya River, Fluvial Geomorphology, River Terrace

Başvuru/Submitted: 07.07.2020 • Revizyon Talebi/Revision Requested: 28.10.2020 • Son Revizyon/Last Revision Received: 30.10 .2020 • Kabul/Accepted: 20.11 .2020 - Online Yayın/Published Online: 22.12 .2020

Sorumlu yazar/Corresponding author: Ebubekir KARAKOCA / ebubekir.karakoca@bilecik.edu.tr

Atıf/Citation: Karakoca, E., \& Uncu, L. (2020). Orta Sakarya vadisi akarsu seki sistemlerinin morfometrik ve sedimantolojik özellikleri (İnhisar-Gemiciköy Arası, Bilecik). Cografya Dergisi, 41, 165-177. https://doi.org/10.26650/JGEOG2020-0057 


\section{EXTENDED ABSTRACT}

River systems are areas where changes in both the erosion and accumulation processes can be observed over short distances. In particular, global climatic changes, sea level changes and local and/or regional tectonic movements during Quaternary have been recorded in river valleys (Schumm et al., 2000; Vandenberghe, 2002; Westaway et al., 2003). The most important geomorphological units that these records have kept are the terrace systems responsible for the deposition and splitting processes. For this reason, quantitative studies in river valleys, (sedimentological analyzes, morphometric calculations and dating) based on field observations of the terrace systems, have great importance for understanding the Quaternary period.

By its geographical location, Turkey is located in the temporal-subtropical zone, which is the most determinant force on geomorphological forming in rivers terraces. Therefore, large river valleys were greatly affected by hydrological changes, induced by climate changes in Quaternary and local/regional tectonic movements, that developed in parallel with the rising tendency of Anatolia. As a result, terrace systems (which are widely observed) have been developed throughout large river valleys. The significantly differ in origin and characteristics.

Studies on river terraces in our country started in the 1940s and increased rapidly in recent years. These studies (Illgüz, 1940; Pfannenstiel, 1941; İnandık, 1955; Akkan, 1970; Erol, 1973), which were based on the geomorphological and sedimentological features of landforms, have gained a quantitative dimension, including geochronological data such as deposition/cleavage dates. In Turkey, said studies are still carried out in various sections of large rivers such as the Kızılırmak River (Dogan, 2011; Çiner et al., 2015; Berndt et al., 2018), the Yesilırmak River (Erturaç and Kıyak, 2017; McClain et al., 2017), the Tigris River (Bridgland et al., 2007; Karadoğan and Kuzucuoğlu, 2017), the Gediz River (Westaway et al., 2003; Maddy et al ., 2016; Maddy et al., 2020), Göksu (Avşin et al., 2019), the Melendiz River (Doğan et al., 2019), the Asi River (Bridgland et al., 2012), the Filyos River (McClain et al., 2019) and the Sakarya River (Erturaç et al., 2019a; Erturaç et al., 2019b).

The lower and middle parts of the Sakarya River valley, the largest river of Northwest Anatolia, are also among the areas where terrace systems can be widely observed. Erturaç et al. (2019) detailed the origins and geochronological developments of the terrace systems. They were observed in three steps in the lower part of the Sakarya River, between the Geyve Gorge and Karasu. However, there are not any publications on the terrace systems observed in the central part of the Sakarya River valley. This study aims to fill this gap in literature. It reveals the morphometric and sedimentological features of the terrace systems observed in the $38 \mathrm{~km}$ length part of the middle of the Sakarya River, between the İnhisar and Gemiciköy settlements in Bilecik province.

The terrace steps identified between İnhisar and Gemiciköy are concentrated on three main areas: Yakacık Village, Hamitabat and Gemiciköy. Terrace levels descend in the flow direction of the stream which includes four levels in Yakacık village $(+10 \mathrm{~m},+18 \mathrm{~m},+34$ $\mathrm{m}$ and $+52 \mathrm{~m})$, three levels around Hamitabad $(+12 \mathrm{~m},+24 \mathrm{~m}$ and $+36 \mathrm{~m})$, and two levels in Gemiciköy $(+10 \mathrm{~m}$ and $+19 \mathrm{~m})$. The common feature of these terraces is that they are preserved on a single slope of the river valley, and they do not show regular continuity.

Around Yakacik, gravel scattered on the terrace (at $+52 \mathrm{~m}$ height) was discovered. All other terraces feature alluvial filling terraces with varying thickness. The fillings of the high terraces (S3 and S2) that we detected in the study area begin with channel deposits consisting of coarse-rounded-coarse gravel at the bottom, and continue with small gravel and finely grained flood plain materials. This indicates that when terrace fillings began to accumulate, there was a change from an irregular, but high energy flow, regime to a more regular and weak energy flow regime over time. The fillings belonging to the youngest benches (S4), developed in the immediate vicinity of the valley floor of Sakarya, consist of finely grained flood plain sediments and sands that contain very little gravel, and and they are the work of this low flow regime.

As revealed by Erturaç et al. (2019), in the terrace systems of the lower ground of the Sakarya River, the global climate changes and the sea level changes during the Quaternary period played an important role in the formation of terraces detected in the study area. The first findings of this study revealed that local and/or regional tectonic movements were developed due to the K-G-squeezing regime, which prevailed in the region during the Quaternary. This study also revealed the effects from the formation of the terraces in the middle ground of the Sakarya River. 


\section{GÍRIŞ}

Yeryüzünün şekillendirilmesinde önemli bir paya sahip olan akarsu sistemleri, aynı zamanda Kuvaterner sırasında küresel ölçekte meydana gelen iklim değişmeleri ve genel kaide seviyesi oynamaları ile lokal ve/veya bölgesel tektonik hareketlere en hızlı tepki veren alanları oluşturmaktadır (Schumm vd., 2000; Vandenberghe, 2002; Westaway vd., 2003). Akarsu sistemlerinde gözlenen aşınım ve birikim şekilleri, özellikle seki sistemleri, bu tepkilerin sedimantolojik, stratigrafik, iklimsel, hidrolojik ve jeomorfolojik kayıtlarının tutulduğu doğal arşivler durumundadır.

Bu bağlamda, seki sistemlerinin kökenleri ve oluşum ned

enleri hakkında yapılacak detaylı arazi gözlemleri ve kantitatif çalışmalar (sedimantolojik analizler, morfometrik hesaplamalar ve tarihlendirmeler) Kuvaterner'de meydana gelen çevresel değişmelerin anlaşılmasında büyük önem taşımaktadır. Bunun yanı sıra akarsu sekileri mekânsal ve zamansal olarak birbirleriyle ilişkilendirildikleri takdirde, bulundukları vadilerin jeomorfolojik evrimini ve daha geniş ölçekteki bölgesel jeomorfolojik evrimin anlaşılması için önemli ipuçları sunarlar.

Dünyanın birçok yerindeki akarsu vadilerinde gözlenen seki sistemleri yerbilimciler tarafindan uzun yillardan beri çalışılmaktadır. Ülkemizdeki akarsu sekileri konusundaki çalışmalar, İlgüz (1940) ile başlamış ve özellikle son birkaç on yılda önemli bir artış göstermiştir. Önceleri sekilerin jeomorfolojik ve morfometrik özelliklerine dayalı olan bu çalışmalar (İlgüz, 1940; Pfannenstiel, 1941; İnandık, 1955; Akkan, 1970; Erol, 1973), son yıllarda sekilerin oluşum yaş1 verilerini de kapsayan jeokronolojik bir boyut kazanmıştır. Bu tür çalışmalara konu olan akarsularımız arasında Kızılırmak (Doğan, 2011; Çiner vd., 2015; Berndt vd., 2018), Yeşilırmak (Erturaç ve Kıyak, 2017; McClain vd., 2017), Dicle (Bridgland vd., 2007; Karadoğan ve Kuzucuoğlu 2017), Gediz (Westaway vd., 2003; Maddy vd., 2016; Maddy vd., 2020), Göksu (Avşin vd., 2019), Melendiz (Doğan vd., 2019), Asi (Bridgland vd., 2012), Filyos (McClain vd., 2019) ve Sakarya (Erturaç vd., 2019a; Erturaç vd., 2019b) bulunmaktadır.

Bunlar arasında özellikle Erturaç vd. (2019) tarafindan Sakarya Nehri'nin aşağı çığırında yapılmış olan çalışma, gerek Kuzeybatı Anadolu akarsuları için bir ilk olması gerekse bizim çalışma alanımızla doğrudan bağlantılı olması bakımından ayrı bir önem taşımaktadır. Erturaç vd. (2019)'ne göre, Sakarya Nehri vadisinin Geyve Boğazı ile Karasu arasında kalan kesiminde 3 basamak halinde gelişmiş olan seki sistemlerinin bulunduğunu tespit etmiş ve bunların birikim-yarılma dönemlerini ve yaşlarını, bölgede yapılmış olan diğer Kuvaterner çalışmalarından elde edilen proxy (vekil) kayıtları ve jeokronolojik yöntemleri (Luminesans-OSL, p-IR-IRSL ve radyokarbon) kullanarak ortaya koymuşlardır. Buna göre, söz konusu seki sistemlerinin Kuvaterner sırasındaki iklim dalgalanmaları ve Karadeniz'deki ana kaide seviyesi oynamalarına bağlı olarak oluştuğu sonucuna varmışlardır.

Sakarya Nehri vadisindeki seki sistemleri hakkında Erturaç vd. (2019b)'nin yapmış olduğu bu çalışmanın dışında literatürde önemli bir boşluk bulunmaktadır. Özellikle, Sakarya Nehri vadisinin, literatürde "Orta Sakarya Platoları" (Bilgin, 1980) olarak bilinen sahayı batıdan sınırlayan kesimi jeomorfolojik olarak, lokal havzaları birbirine bağlayan dar ve derin birleştirme boğazları (Hamitabat ve Şeytankaya gibi) ve birkaç basamak halinde gözlenen seki sistemlerinin varlığ ile karakterize edilmektedir.

Çalışma sahası, Sakarya Nehri'nin Orta Sakarya Platoları ile Sündiken Dağları arasında GD-KB yönünde akış gösterdiği, Bilecik iline bağlı İnhisar ilçesi ile Söğüt ilçesinin kuzeyindeki Gemiciköy yerleşmeleri arasında kalan ve yaklaşı $38 \mathrm{~km}$ uzunluğa sahip olan kesimini kapsamaktadır. Coğrafi koordinatlar olarak $40^{\circ} 21^{\prime} 50^{\prime \prime}-40^{\circ} 02^{\prime} 40^{\prime \prime}$ kuzey enlemleri ile $30^{\circ} 00^{\prime} 28^{\prime \prime}$ $30^{\circ} 06^{\prime} 10^{\prime \prime}$ doğu boylamları arasında bulunmaktadır (Şekil 1).

\section{AMAC VE YÖNTEM}

Çalışmanın amacı, Sakarya Nehri vadisinin, Bilecik iline bağlı İnhisar ve Gemiciköy yerleşmeleri arasında kalan kesiminde birkaç basamak halinde tespit etmiş olduğumuz seki sistemlerinin morfometrik ve sedimantolojik-stratigrafik özelliklerini ortaya koyarak bölgenin Kuvaterner sırasındaki jeomorfolojik gelişimi konusundaki çalışmalara bir katkı sunmaktır.

$\mathrm{Bu}$ amaç doğrultusunda, öncelikle çalışma sahasının detaylı morfometrik analizlerini yapabilmek için 1/25.000 ölçekli topografya haritaları (H24 c1-c4-d2-d3 paftaları) kullanılarak 10 $\mathrm{m}$ çözünürlüğe sahip sayısal yükseklik modeli (DEM) hazırlanmıştır. Arazi çalışmalarımız sırasında gözlemlemiş olduğumuz sekilerin koordinat ve yükseklikleri, GPS (Garmin, Oregon 650 marka) ve el metresi kullanılarak ölçülmüş, daha sonra ArcMap 10.5 programı yardımıyla hazırlamış olduğumuz altlık üzerine işlenmiştir. Böylece, hazırlanan profiller yardımıyla seki basamaklarının yüksekliği ve alansal dağılışlarındaki farklılıklar ortaya konulmuştur. Sekilerin sedimantolojik özellikleri ve stratigrafik dizilimi ise arazide yapılan gözlemler sırasında belgelenmiştir. 


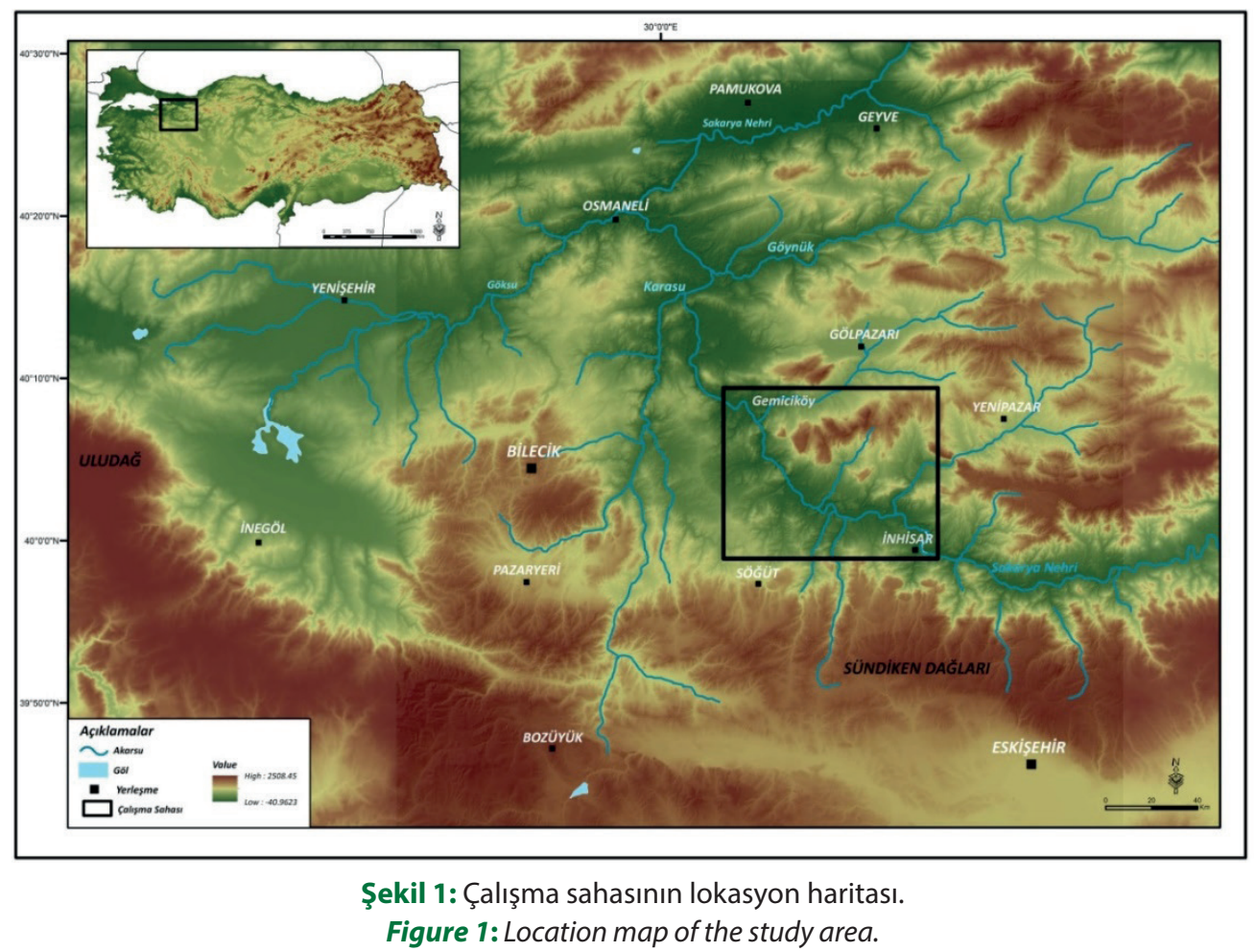

Çalışma sahasında, Sakarya Nehri'nin açmış olduğu ve seki oluşumlarını büyük ölçüde kontrol eden dar ve derin boğazlara uygulanan morfometrik analizler (VF-vadi tabanı genişliği / vadi yüksekliği oranı) ile akarsuyun yatağı boyunca almış olduğumuz eğim kırıklıklarını gösteren boyuna profil ise bunların oluşum süreçleriyle sahanın tektonik özellikleri hakkında önemli bilgiler vermiştir.

\section{BULGULAR}

\subsection{Jeolojik ve Jeomorfolojik Özellikler}

Çalışma sahası, Kuzeybatı Anadolu'da D-B yönünde uzanan, güneyde İzmir-Ankara Sütur Kuşağı, kuzeyde ise İntra-Pontid Kuşağı ile sınırlandırılmış olan "Sakarya Kıtası tektonik kuşağı" içerisinde yer almaktadır (Okay, 1989). Burada jeolojik yapıyı oluşturan kayaç toplulukları, Paleozoyik yaşlı granit ve Söğüt metamorfitleri (mermer ve şistler), Mesozoyik yaşlı Bilecik kireçtaşları, Orta Eosen-Alt Miyosen yaşlı Gemiciköy formasyonu (akarsu-gölsel çökeller) ve bunları uyumsuz bir şekilde örten Kuvaterner yaşlı birimlerden oluşmaktadır (Şekil 2).

Bölgede en yaşlı jeolojik formasyonlar ile temsil edilen Sakarya kıtasının bulunduğu sahayı çevreleyen Mesozoyik denizleri içerisinde biriktirilmiş olan materyaller (kireçtaşı ve flişler) Alpin orojeneze bağlı olarak, Miyosen başlarında su yüzeyine çıkarak tamamen karalaşmıştır. Bunu takip eden Orta
Miyosen sırasındaki sıcak ve nemli iklim koşulları altında, bölgede geniş alanlar kaplayan Mesozoyik yaşlı Bilecik kireçtaşları üzerinde karstlaşma gelişmeye başlamıştır. Orta-Üst Miyosen'de Arap Plakası'nın Anadolu'ya çarpmasıyla başlayan Neotektonik dönem sırasında Anadolu'nun bütünüyle yükselmesine koşut olarak bölge, K-G yönlü sıkışmaların etkisi altına girmiş ve Üst Miyosen-Alt Pliyosen boyunca meydana gelen şiddetli tektonik hareketlere bağlı olarak, bloklar halinde parçalanmıştır. Böylece yükselen bloklar Orta Sakarya Platoları'nın, çöken bloklar ise lokal havzalarının şekillenmesine neden olmuştur.

Üst Pliyosen'de bölgeye yerleşen Sakarya Nehri ve kolları, süregelen tektonik hareketler sonucunda oluşan zayıf direnç alanlarını ve karstlaşma olaylarının sağlamış olduğu imkânları kullanarak Orta Sakarya Platolarına hızla gömülmüş ve boğazlar oluşturmuştur. Bilgin (1980), bu boğazların Sakarya Nehri'nin Orta Sakarya Platoları'na hızla gömülmesi sonucunda oluşmuş olan epijenik boğazlar olduğunu ileri sürmüştür. Çalışma alanı içerisinde kalan Harmankaya Kanyonu'na uyguladığımız morfometrik indis (vadi tabanı genişliği / vadi yüksekliği oranı) sonucunda elde edilen yüksek Vf değeri (ortalama 0,04 ), önce tektonizmanın etkisi ile sahada yükselmenin gerçekleştiğini, sonrasında akarsu yatağının şiddetli bir şekilde derine doğru gömüldüğünü göstermiştir (Uncu ve Karakoca, 2019). Bununla birlikte, kanyonun içerisinde yüksekliği 20 metreye ulaşan basamakların bulunması ve tabanındaki sıcak su çıkışları lokal tektonik olayların devam ettiğini göstermektedir. Bu durum, 


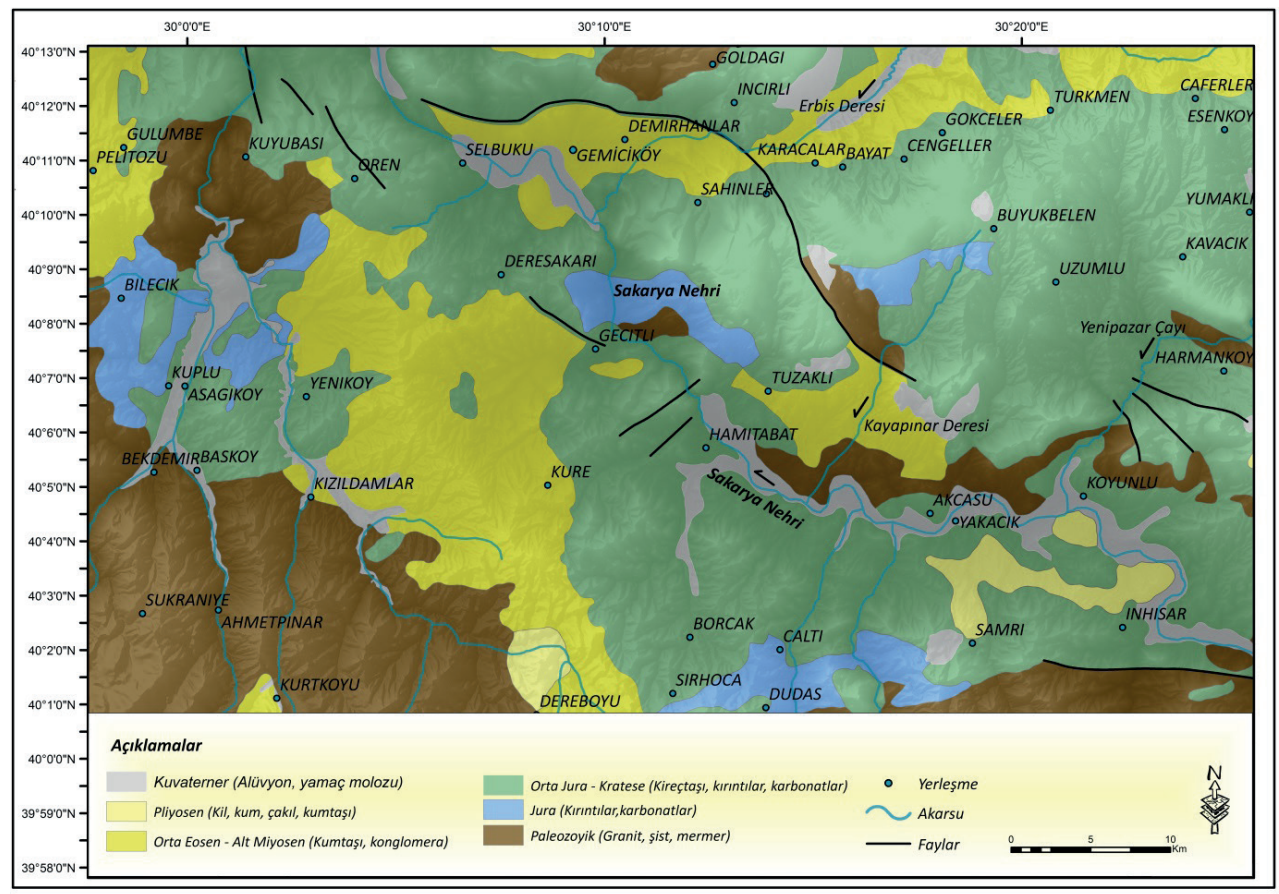

Şekil 2: Çalışma sahasının jeoloji haritası.

Figure 2: Geological map of the study area.

Harmankaya Kanyonu gibi, Şeytankaya ve Hamitabat Boğazları'nın oluşumunda da epijenez olayının yanı sıra antesedans olayının rolü bulunduğunu kanıtlamaktadır (Şekil 3).

Bölgedeki lokal tektonik etkilerin varlığı, DSİ sondajlarına ait veriler incelendiğinde de dikkati çekmektedir. $\mathrm{Bu}$ verilere göre, Sakarya Nehri'nin boğazları terk ettiği alanlarda hem alüvyal dolguların kalınlığının hem de oturdukları anakayanın litolojisinin değiştiğini göstermektedir. Şeytankaya Boğazı'nın çıkışındaki 59527 nolu sondajda, yaklaşık $30 \mathrm{~m}$ kalınlıktaki dolgular Orta Jura-Alt Kretase yaşlı Bilecik kireçtaşları üzerine oturmaktadır. Buna karşın, Gemiciköy yakınlarındaki Yukarıkumlar mevkiindeki 59524 ve 59525 nolu sondajlarda ise dolgu kalınlığı 40 m.ye ulaşmakta ve depolar Orta Eosen-Alt Miyosen yaşlı Gemiciköy formasyonunun üzerine uyumsuz bir şekilde gelmektedir (Şekil 4).

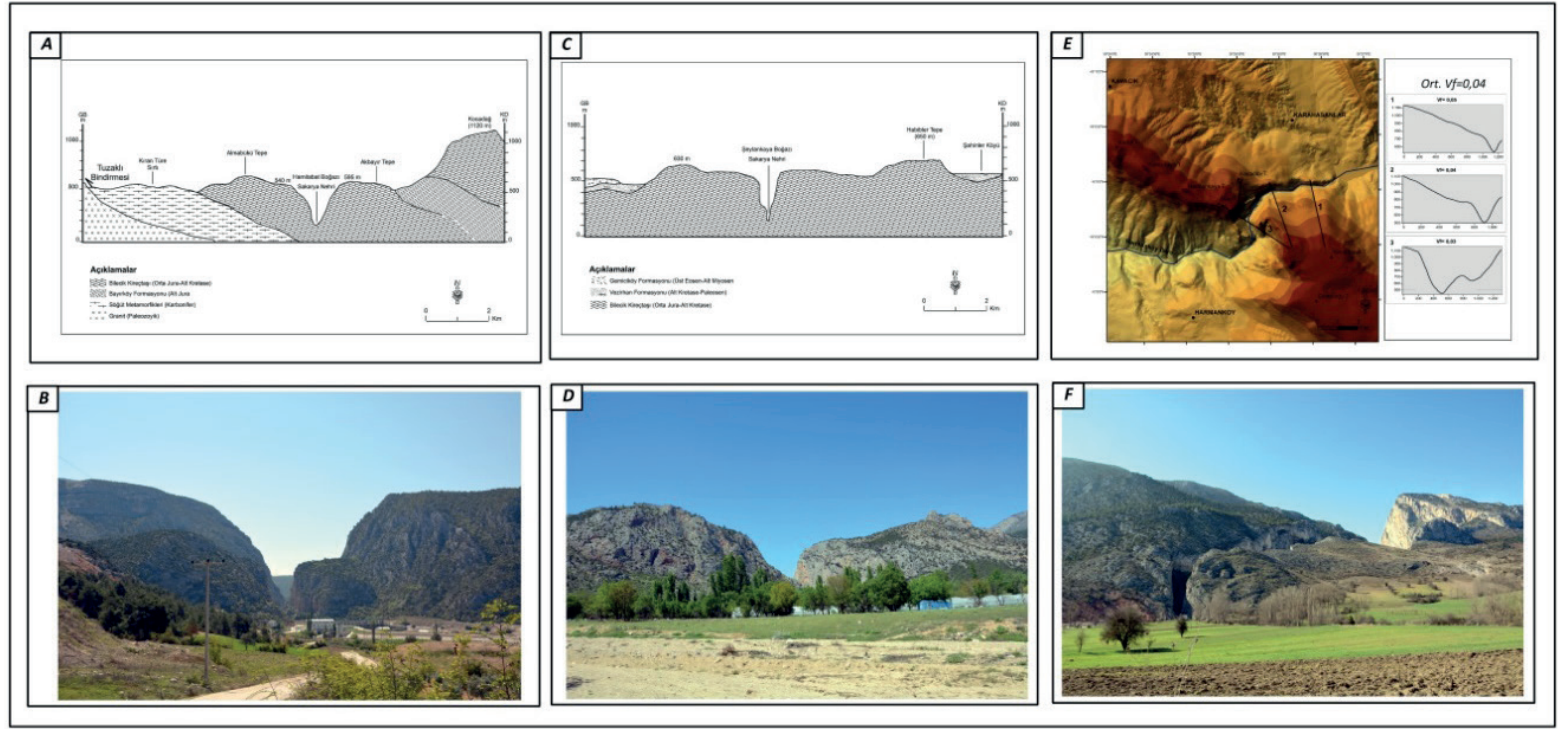

Şekil 3: Sakarya Nehri tarafından açılmış olan Şeytankaya boğazı (A-B), Hamitabat boğazı (C-D) ile Harmankaya Kanyonu'nun (E-F) enine kesitleri ve morfometrik özellikleri.

Figure 3: Cross-sections and morphometric characteristics of Şeytankaya gorge, Hamitabat gorge (C-D) and Harmankaya Canyon opened by Sakarya River. 


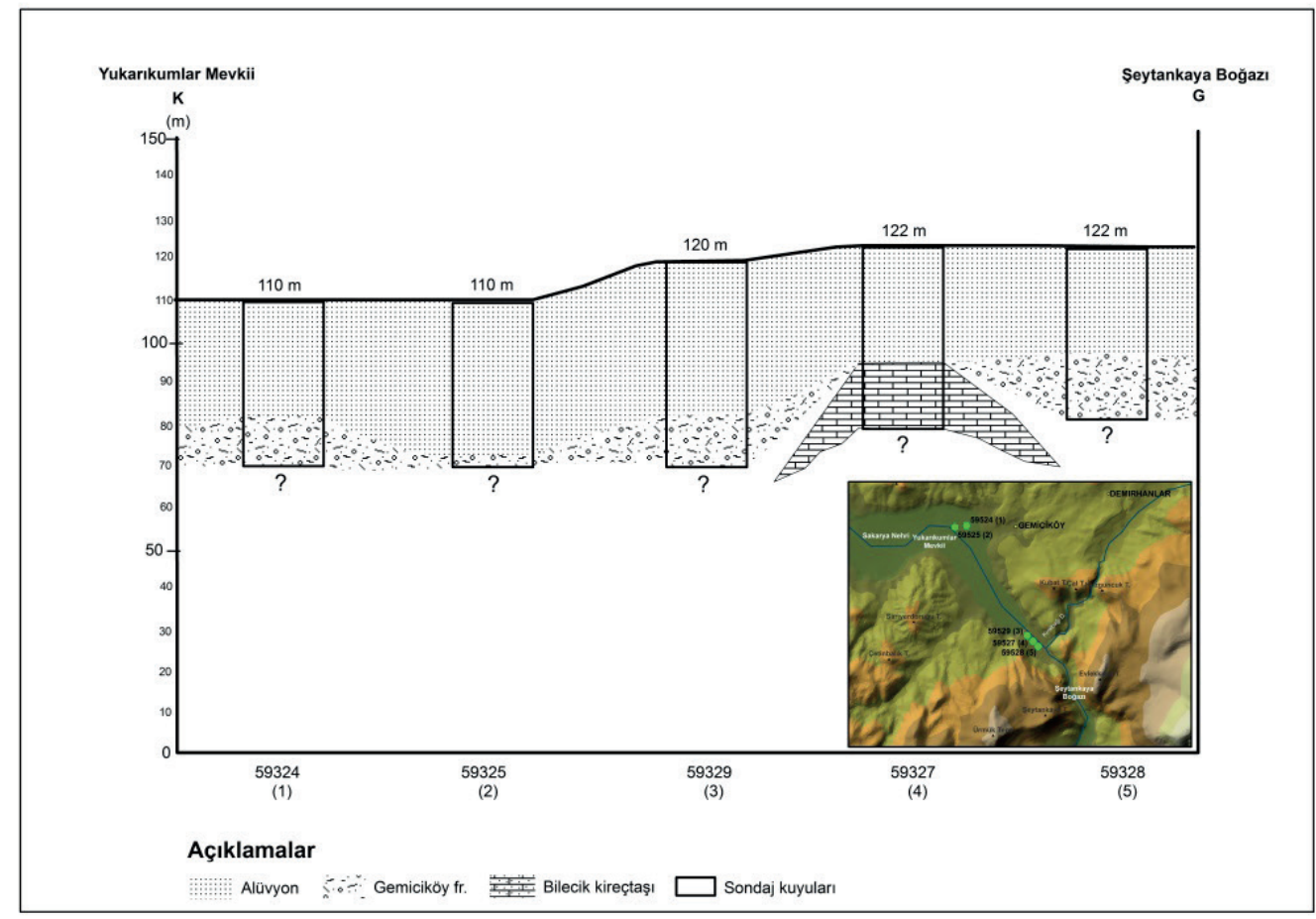

Şekil 4: Gemiciköy ile Şeytankaya boğazı arasında DSi (Devlet Su İşleri Genel Müdürlüğü) tarafından yapılmış olan sondaj çalışmalarına ait bulguları gösteren kesit.

Figure 4: Cross-section showing the findings of the sounding studies carried out by DSI (The General Directorate of State Hydraulic Works) in Gemiciköy Village and Şeytankaya gorge.

Şeytankaya ve Hamitabat boğazlarının oluşumuyla birlikte, Orta Sakarya havzasının bu kesiminde bulunan kapalı havzalar Sakarya Nehri ve kolları tarafından birleştirilerek dış drenaja açılmıştır. Böylece havzalardaki aşınım ve birikim süreçleri Sakarya Nehri tarafından kontrol edilmeye başlanmıştır.

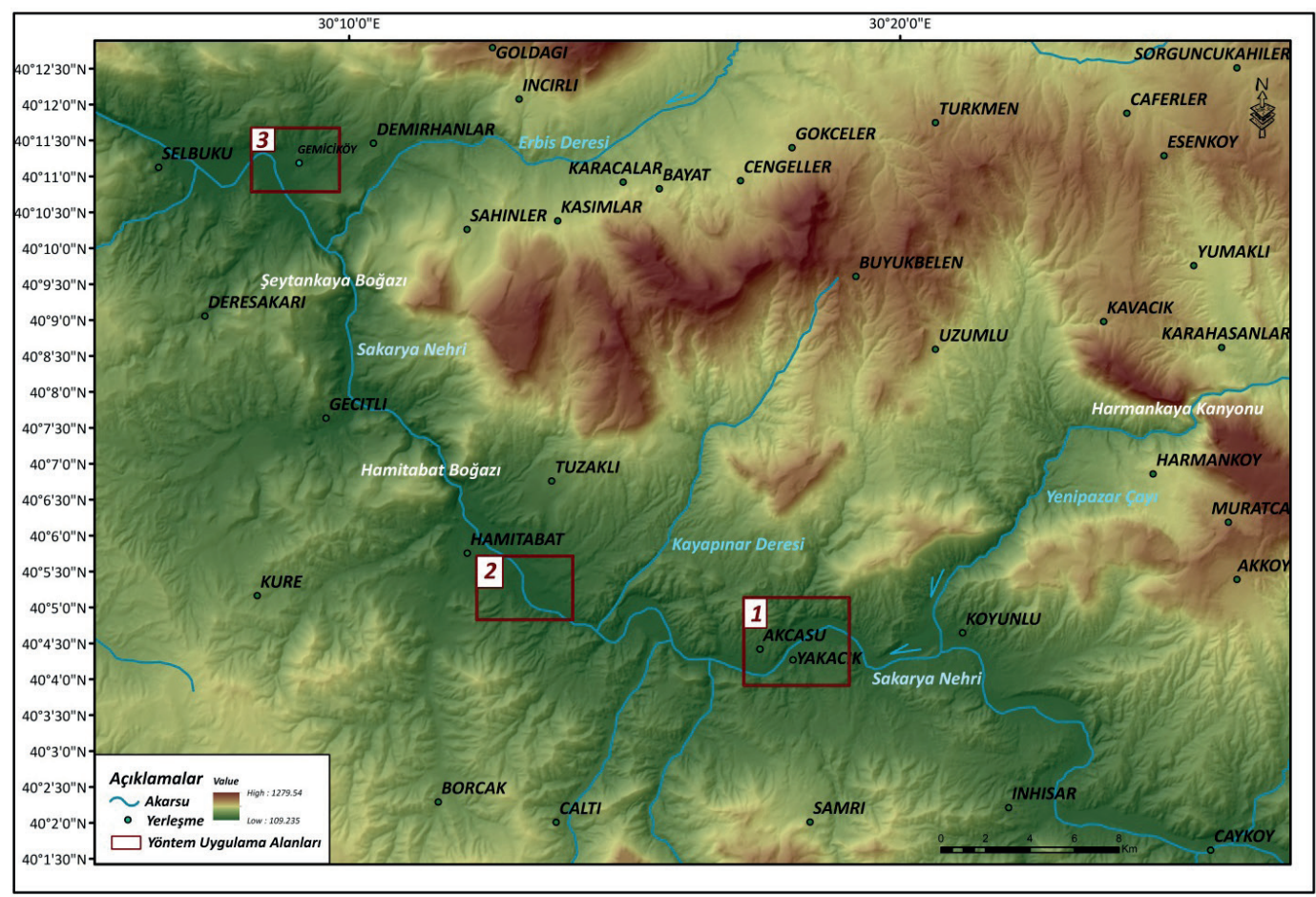

Şekil 5: Çalışma alanında seki sistemlerinin tespit edilebildiği sahalar.

Figure 5: Terrace systems found in the study area. 


\subsection{Seki Sistemlerinin Morfometrik ve Sedimantolojik Özellikleri}

Sakarya Nehri vadisinin İnhisar ve Gemiciköy arasında kalan 38 km.lik bölümünü kapsayan çalışma alanında tespit edilen seki basamakları 3 sahada; Yakacık köyü, Hamitabat ve Gemiciköy çevresinde yoğunlaşmaktadır (Şekil 5). Sekiler, akarsuyun akış yönünde vadi tabanının yüksekliğinin de azalmasına bağlı olarak, Yakacık köyünde 4 seviye, Hamitabat çevresinde 3 seviye ve Gemiciköy'de ise 2 seviye halinde bulunmaktadır. Hamitabat çevresindekiler hariç Yakacık ve Gemiciköy çevresindeki sekiler vadi boyunca genelde tek bir yamaçta korunmuştur. Ayrıca, vadinin bazı kesimlerindeki sekiler süpürülmüş olmalarından dolayı, vadi boyunca düşey ve yatay doğrultuda düzenli bir devamlılık göstermemektedir.

İnhisar'ın kuzeybatısında bulunan Yakacık ve Akçasu köyleri çevresinde, Sakarya Nehri vadisini nispeten genişleterek akmakta ve yan kollar almaktadır. Burada deniz seviyesinden 150 m yükseklikte akmakta olan Sakarya Nehri'nin vadi tabanından itibaren yükseklikleri; +52 m (S1), +34 m (S2), +18 m (S3) ve $+10 \mathrm{~m}$ (S4) olarak ölçülmüş 4 seki basamağ1 tespit edilmiştir (Şekil 6). Buradaki seki basamakları, Sakarya'nın akış

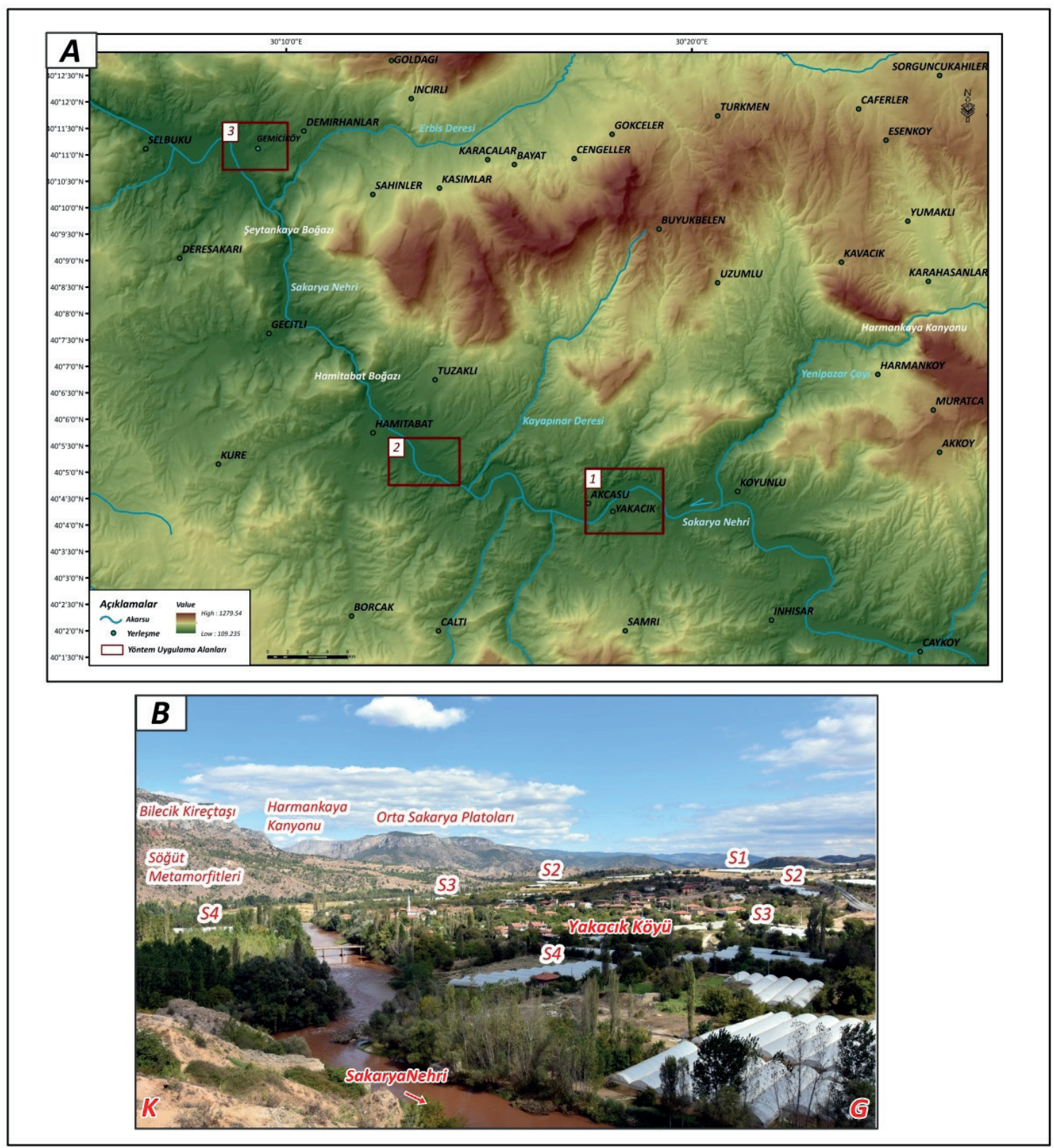

Şekil 6: Yakacık köyü (A-1) çevresinde vadi tabanından +52 m (S1), +34 m (S2), +18 m (S3), +10 m (S4) yükseklikte yer alan seki seviyeleri (A ve B), Figure 6: Terrace levels (A and B) located at a elevation of $+52 \mathrm{~m}(\mathrm{~S} 1),+34 \mathrm{~m}(\mathrm{~S} 2),+18 \mathrm{~m}(\mathrm{~S} 3),+10 \mathrm{~m}$ (S4) from the valley plain around Yakacık village (A-1). 
yönünde solda Paleozoyik yaşlı Sögüt metamorfitleri üzerine açısal bir uyumsuzlukla gelmekte ve diğer üç seviyenin aksine sadece en alçaktaki sekiler (S4) akarsuyun her iki yakasında da gözlenebilmektedir.

En yüksekte bulunan seki basamağı (S1), tipik alüvyal seki dolgusundan yoksundur ve basamak yüzeyinde yayılmış olan ince bir çakıl örtüsü ile karakterize edilmektedir. Bu alandaki diğer seki basamakları (S2, S3 ve S4) ise nispeten daha yaygın olarak gözlenmektedir. Yakacık köyü, büyük ölçüde +34 (S2) ve +18 (S3) metrelerdeki seki basamaklarının üzerinde kurulmuştur (Şekil 6). Özellikle Yakacık köyü içerisindeki bir yol yarmasında aflörman veren $+18 \mathrm{~m}$ sekisinde (S3) alüvyal dolgunun kalınlığ 2 metreyi bulmaktadır. Bu alüvyal dolgu, biniklenmenin (çakıl yönelimi/imbrikasyon) nehrin kaynak kısmına doğru olduğu, ince-orta boy çakıllardan oluşan yatak dolgusu çökelleri ve onların üzerine gelen kil-silt boyutundaki taşkın ovası sedimanlarından oluşan iki bölümden meydana gelmekte ve en üst kısımda gelişkin bir toprak örtüsü bulunmaktadır (Şekil 7). Yakacık çevresindeki seki basamaklarının üzerinde, Sakarya Nehri vadisinin bu kesiminde tarıma elverişli alanların sınırlı olması nedeniyle yoğun seracılık faaliyetleri yürütülmektedir.

Çalışma sahası içerisinde seki basamaklarının gözlendiği ikinci alan Hamitabat köyü çevresidir. Burada deniz seviyesinden
140 m yükseklikte bulunan Sakarya Nehri'nin vadi tabanından itibaren $+36 \mathrm{~m}(\mathrm{~S} 1),+24 \mathrm{~m}(\mathrm{~S} 2)$ ve $+12 \mathrm{~m}$ (S3) yükseklikte 3 seki seviyesi tespit edilmiş̧ir. Bu sahada tespit edilen seki seviyeleri kalın alüvyal dolgulardan oluşmakta ve Mesozoyik yaşlı Bilecik kireçtaşlarının üzerine açısal uyumsuzlukla gelmektedir.

Bunlardan özellikle +24 m yükseklikteki seviye (S2), yol yarmasında görüldüğü üzere, yaklaşık 3-4 metre kalınlıkta bir alüvyal dolguya sahiptir ve sedimantolojik olarak birbirinden belirgin bir şekilde ayrılan iki bölümden oluşmaktadır. Bu bölümlerden altta bulunan yaklaşık olarak 2 metre kalınlığında, ağırlıklı olarak tane destekli ve iyi boylanmış, yatay ve paralel katmanlanmış orta çakıllardan üstte bulunan ise yaklaşık 1.5 metre kalınlığa sahip, yatay ve paralel laminalanmış kil-silt boyutunda taşkın ovası depolarından meydana gelmektedir (Şekil 8). Bu durum, akarsuyun akımının yüksek enerjiliden düşük enerjiliye doğru değiştiğini göstermektedir.

Çalışma alanında sekilerin yaygın olarak gözlendiği üçüncü saha olan Gemiciköy çevresinde ise deniz seviyesinden $124 \mathrm{~m}$ yükseklikte bulunan Sakarya Nehri'nin vadi tabanından itibaren +19 m (S1) ve +10 m (S2) yüksekte bulunan iki seki basamağ1 tespit edilmiştir (Şekil 9). Seki basamakları genelde Orta EosenAlt Miyosen yaşlı Gemiciköy formasyonunu oluşturan karasal depoların üzerine açısal bir uyumsuzlukla gelmektedir.

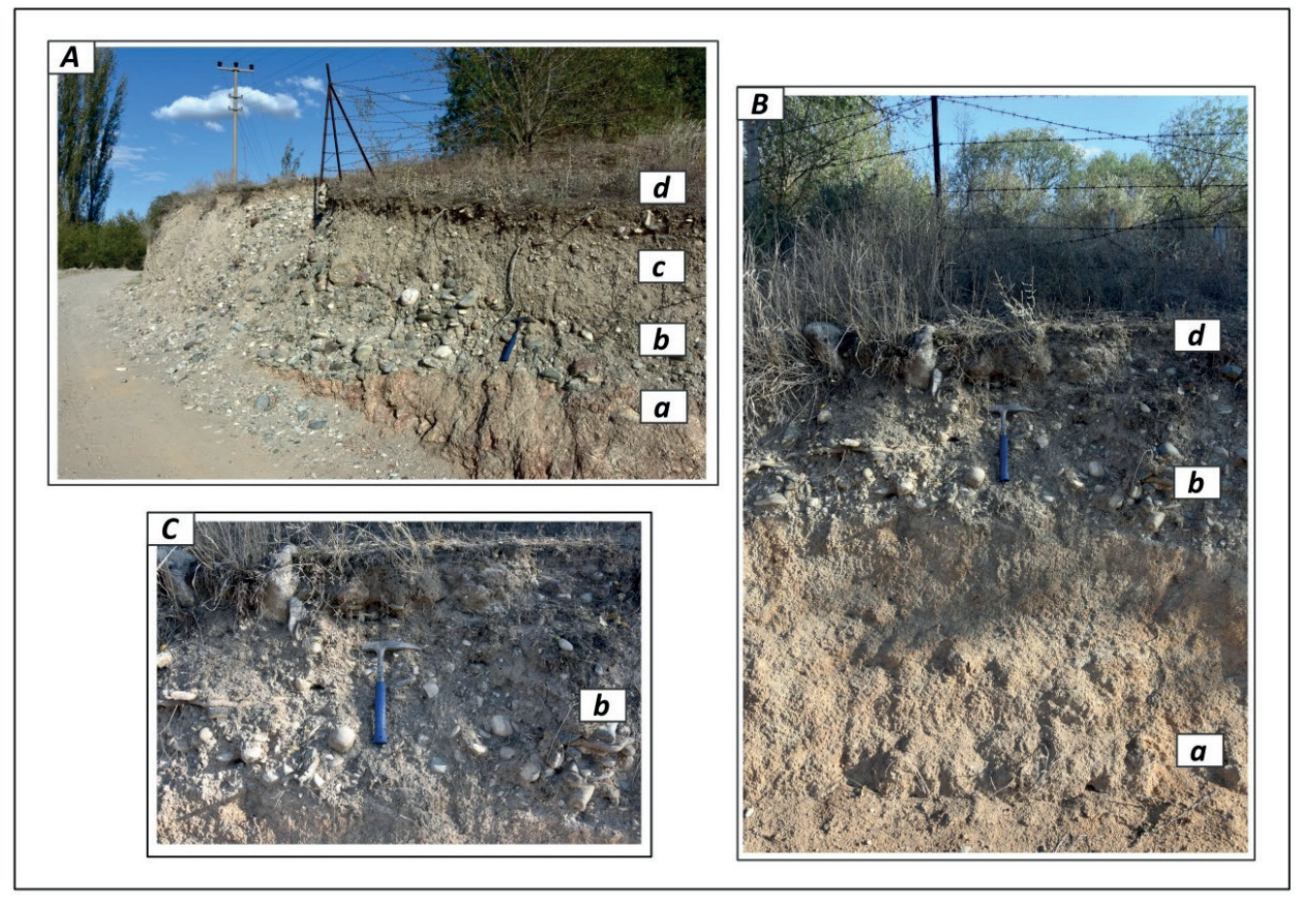

Şekil 7: Yakacık köyü yakınlarında S3 numaralı seki deposunun Paleozoyik yaşlı Söğüt metamorfitleri (a) ile dokanağı; çapraz katmanlı, ince-orta çakıl içeren akarsu yatağı çökellerinden (b) ince çakıl, killi siltli taşkın ovası çökellerine geçişi (c) ve toprak örtüsü (d).

Figure 7: The contact and the Paleozoic Söğüt metamorphics (a) of terrace deposite S3 near Yakacık village; transition from cross-bedded river bed sediments containing thin to medium gravel (b) to fine gravel, clayey silty flood plain deposits (c) and ground cover (d). 


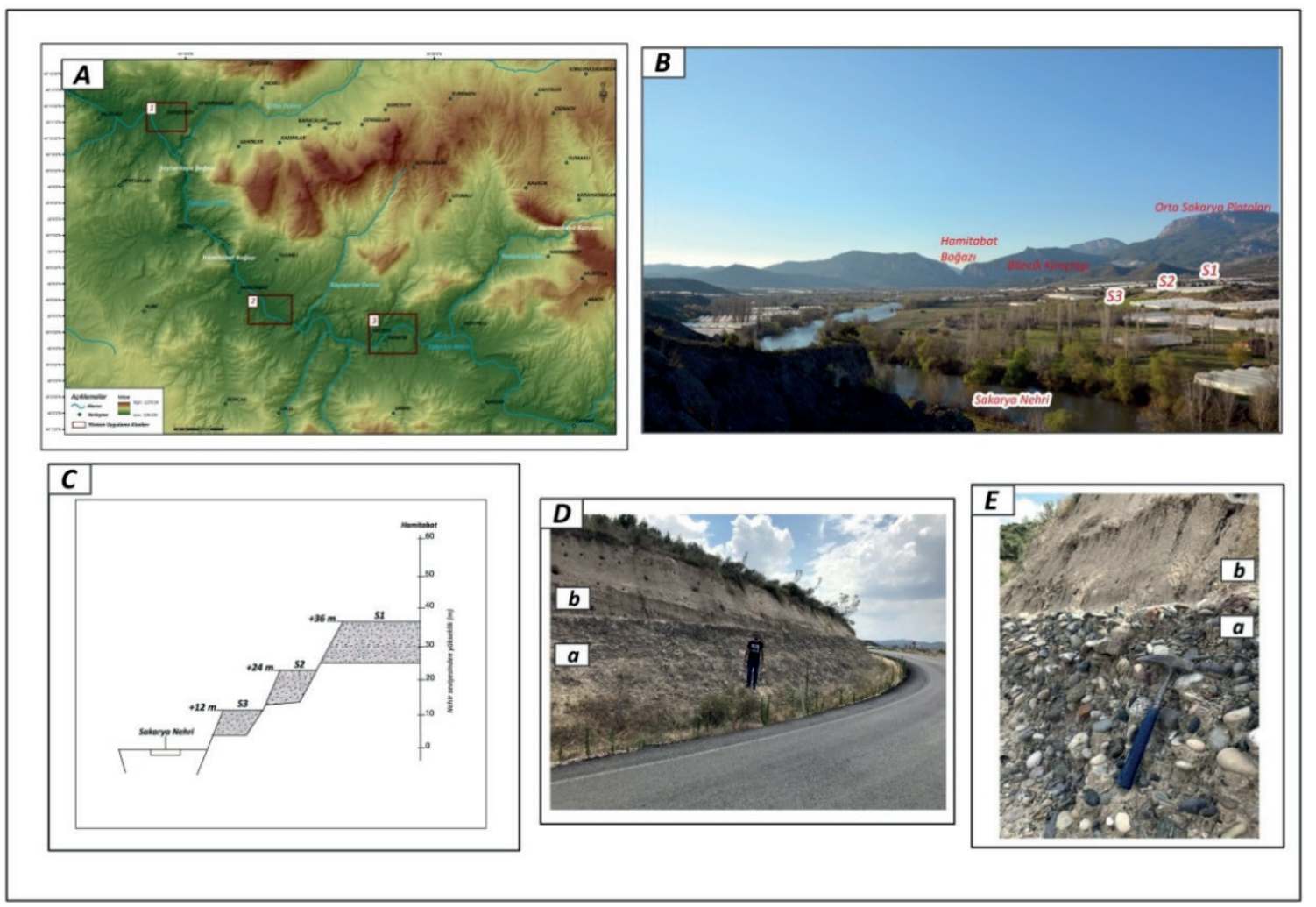

Şekil 8: Hamitabat köyü (A-2) çevresinde vadi tabanından +36 m (S1), +24 m (S2) ve +12 m (S3) yükseklikte bulunan seki seviyeleri. Figure 8: Terrace levels located at a elevation of $+36 m(S 1),+24 m(S 2)$ and $+12 m(S 3)$ from the valley plain around Hamitabat Village (A-2).
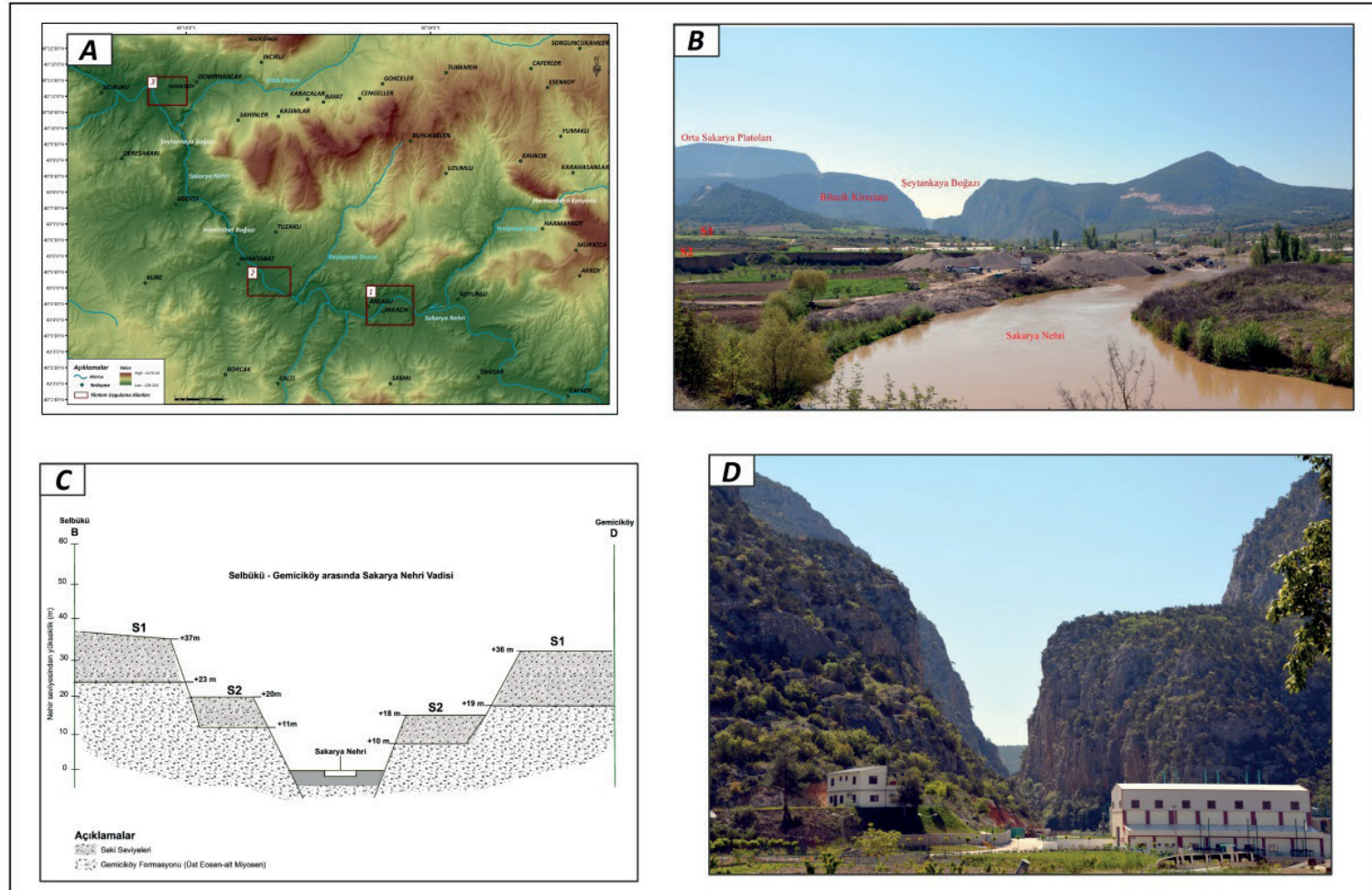

Şekil 9: Gemiciköy (A-3) çevresinde vadi tabanından +19 m (S1) ve +10 m (S2) yükseklikte yer alan seki seviyelerinin kesiti (B ve C) ve Şeytankaya Boğazında meydana gelen basamaklanma yüzeyi (D).

Figure 9: The cross-section of the terrace levels (B and C) located at the elevation of $+19 m(S 1)$ and $+10 \mathrm{~m}$ (S2) from the valley plain around Gemiciköy surface $(A-3)$ and the stepping surface $(D)$ occurring in Şeytankaya gorge. 


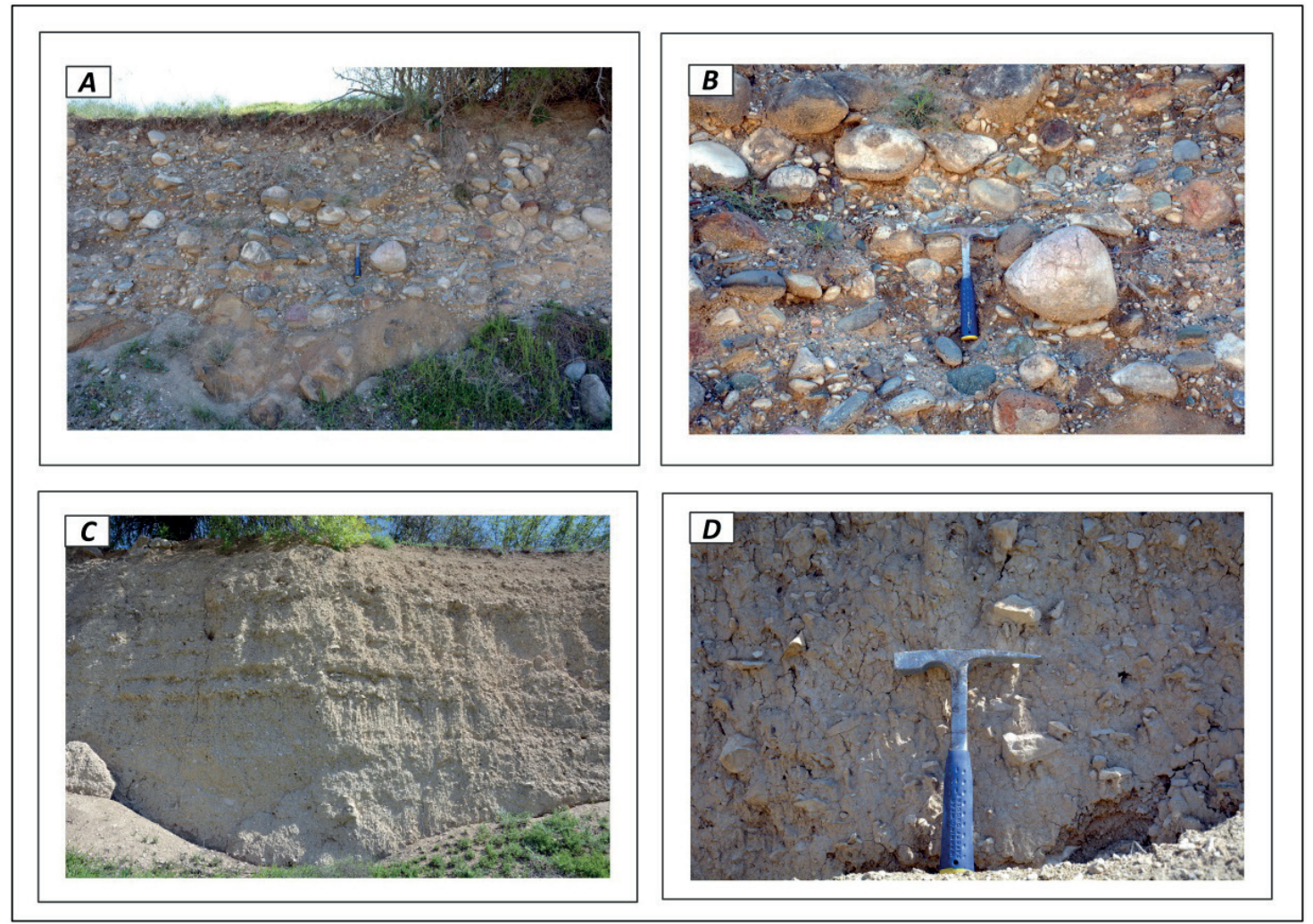

Şekil 10: Gemiciköy kesitinde yüksek seki (S1) deposu (A), yarı yuvarlanmış-yuvarlanmış, ince-orta boy çakıllardan oluşurken yer yer iri çakıl boyutundaki malzemeler de bulunmaktadır (B); Gemiciköy kesitindeki alçak seki (S2) deposu ise köşeli taşlardan ve kil-silt boyutundaki malzemelerin bir araya gelmesi sonucu oluşmuştur (C ve $D)$.

Figure 10: Gemiciköy cross-section consists of upper terrace (S1) deposit (A), semi-rounded-rolled, thin-medium sized pebbles, while there are also large gravel-sized materials (B); the lower terrace (S2) in the Gemiciköy section was formed as a result of the combination of angular stones and clay-silt materials (C and D).

Yüksek sekiyi (S1) oluşturan yaklaşık olarak 1 metre kalınlığındaki seki deposu, yer yer iri çakıl boyutundaki yatak dolguları içeren yarı yuvarlanmış-yuvarlanmış ince-orta boy çakıllardan oluşmakta ve büyük oranda iyi çimentolanmış bir konglomera özelliği göstermektedir (Şekil 10). Çalışma sahasinda halen Yukarıkumlar mevkiinde kum ocağı olarak işletilmekte olan alçak sekiyi (S2) meydana getiren depoların kalınlığ1 ise yaklaşık olarak 5 metredir. Alçak seki (S2) malzemeleri ise daha çok irili ufaklı köşeli taşlar ve kil-silt boyutundaki malzemelerden oluşmaktadır. Düşük açı1ı düzlemsel çapraz katmanlanma gösteren depo içerisinde tane destekli ince çakıl tabakaları görülmektedir. Bu deponun en çarpıcı özelliği, masif katmanlanmış çakıllar içerisinde yer yer kesintili şekilde gözlenen ve dönem dönem durgunlaşan akışın göstergesi olan kil-silt bantlarının varlığıdır (Şekil 10).

\section{TARTIŞMA VE SONUÇ}

Orta Sakarya Platoları olarak adlandırılan ünitenin en batı kısmında bulunan araştırma alanı, genel konumu itibariyle kuzeyden Kuzey Anadolu Fay Zonu, güneyden ise Eskişehir Fay
Zonu olarak bilinen Türkiye'nin önemli ve son derece aktif iki doğrultu atımlı fay zonu arasında kalan bir bölgede bulunmaktadır. Bu nedenle, Neotektonik dönem boyunca bölge bir yandan K-G yönlü sıkışma tektoniği rejiminin etkisi altında yükselirken diğer yandan da bloklanmalara uğramıştır.

Sekilere ait konum ve yaş verileri kullanılarak bir bölgedeki yıllık sabit yükselim hızının hesaplanması bölgesel tektonik aktivitenin belirlenmesinde en somut bulgudur. Türkiye'deki seki sistemleri kullanılarak yapılan çalışmalarda bölgesel yükselim hızı, Kuzey Anadolu Fayının kuzeyinde bulunan Kızılırmak'ta $0.28 \pm 0.07 \mathrm{~mm} / \mathrm{yll}$ (Berndt vd., 2018), Filyos Nehri'nde $0.29 \pm$ $0.03 \mathrm{~mm} / \mathrm{y} 1 \mathrm{l}$ (McClain vd., 2019), Kuzey Anadolu fayının güneyinde kalan Sakarya Nehri'nin aşağı çı̆̆ırında ortalama 0.73 \pm 0.06 mm/y1l (Şahiner vd., 2018; Erturaç vd., 2019b) ve çalışma sahası içerisinde kalan bölgede ise İnhisar yakınlarında $0.46 \mathrm{~mm} /$ yıl, Hamitabat yakınlarında 0.75 mm/yıl (Erturaç vd., 2009a) olarak hesaplanmıştır. Buna göre, kısa mesafede bu kadar büyük farklılıklar $(0.46 \mathrm{~mm} / \mathrm{y} 11-0.75 \mathrm{~mm} / \mathrm{yl})$ gösteren yükselim hızı, buradaki seki oluşumlarında ve metrik farklılıklarda bölgesel tektonik aktivitenin önemli rol oynadığını göstermektedir. 
Çalışma alanı içerisinde Sakarya Nehri'nin vadi tabanından itibaren, Yakacık köyü çevresinde dört $(+10 \mathrm{~m},+18 \mathrm{~m},+34 \mathrm{~m}$ ve $+52 \mathrm{~m})$, Hamitabat köyü çevresinde üç (+12 m, $+24 \mathrm{~m}$ ve $+36 \mathrm{~m})$ ve Gemiciköy çevresinde iki ( $+10 \mathrm{~m}$ ve $+19 \mathrm{~m})$ seviye halinde gözlenebilen seki basamakları tespit edilmiştir. Sakarya Nehri'nin vadi tabanı esas alındığında, Yakacık Köyü'nde tespit ettiğimiz son iki seki basamağı (S3 ve S4) ile Gemiciköy çevresinde tespit ettiğimiz seki seviyeleri ( $\mathrm{S} 2$ ve S1) morfometrik olarak bir benzerlik göstermektedir. Buna karşı, çalışma alanının orta kesiminde yer alan Hamitabat köyü çevresinde ise benzer seki basamakları diğerlerinden daha yüksekte ( $\mathrm{S} 3,+2 \mathrm{~m}$. ve S2, +4-5 m.) bulunmaktadır. $\mathrm{Bu}$ durum, Hamitabat yakınlarında yıllık yükselim hızının $(0.75 \mathrm{~mm} / \mathrm{y} 1)$ çalışma alanındaki diğer sahalardan (İnhisar'da $0.46 \mathrm{~mm} / \mathrm{y} 1$ ) daha yüksek olmasından kaynaklanmaktadır.

Bunun yanı sıra, İnhisar-Gemiciköy arasında Sakarya Nehri'nin yatağı boyunca alınmış olan boyuna profilin, aynı litolojik birim (alüvyon) içerisinde düzenli bir eğim göstermesi beklenirken bunun tersine eğimde yer yer kırıklıkların bulunması da ancak lokal tektonik hareketlerin etkisi ile açıklanabilir (Şekil 11).

Hamitabat ve Gemiciköy yakınlarında seki dolgularında biniklenmenin (çakıl yönelimi/imbrikasyon) belirlenememesi, Yakacık ile Gemiciköy çevresindeki seki basamaklarının akarsuyun sadece bir yakasında bulunması, Hamitabat çevresinde ise seki basamaklarının akarsuyun her iki yakasında bulunmasına rağmen seviyelerinin uyumsuzluklar göstermesi ve akarsu yatağındaki ötelenmeler (Yakacık-Akçasu köyleri arasında) çalışma sahasında lokal tektonik aktivitelerin diğer göstergeleri durumundadır.
Kuvaterner sırasında da devam eden bölgesel yükselmeye bağlı olarak, Sakarya Nehri tarafından bir yandan çalışma sahasındaki boğazlar derinleştirilirken diğer yandan bu boğazlar tarafindan kontrol edilen vadinin nispeten genişlediği alanlardaki alüvyal dolguları yarmıştır. Bunun yanı sıra, Erturaç vd. (2019b) tarafından da ortaya konulduğu üzere, Kuvaterner'deki iklimsel değişimler (sıcak-soğuk iklim geçişleri) bir yandan Karadeniz'deki seviye oynamalarına bağlı olarak kaide seviyesini kontrol ederken diğer yandan da Sakarya Nehri'nin su potansiyelini dolayısıyla taşıdığı sediment miktarını düzenleyerek kazılma-birikme döngülerini şekillendirmiştir.

Sakarya Nehri vadisi boyunca düzensiz bir dağılış gösteren seki basamaklarından Yakacık çevresinde tespit etmiş olduğumuz +52 m. yükseklikte ve üzerinde dağınık halde çakıllar bulunan seviye (S1) dışında kalan diğer tüm sekiler kalınlığı yer yer değişen dolgu sekisi özelliği göstermektedir. Çalışma sahası içerisinde tespit ettiğimiz yüksek sekilere ( $\mathrm{S} 3$ ve $\mathrm{S} 2$ ) ait dolgular, sedimantolojik olarak altta yarı yuvarlanmış-yuvarlanmış iri çakıllardan oluşan akarsu yatağı depolarıyla başlamakta üste doğru ise küçük çakııllar ve ince taneli taşkın ovası materyalleriyle devam etmektedir. Bu durum, seki dolgularının biriktirilmeye başladığı dönemde, daha bol yağışlı ve nemli iklim koşullarına bağlı olarak düzensiz ancak yüksek enerjili bir akış rejiminin olduğunu göstermektedir. Ancak, günümüze doğru yaklaştıkça iklim koşullarının daha ılıman ve sıcak bir özellik kazanmasıyla birlikte daha düzenli ve zayıf enerjili bir akış rejimine doğru değişim göstermiş̧ir. Sakarya'nın vadi tabanının hemen yakınında gelişmiş bulunan en genç sekilere (S4) ait dolgular ise tamamen bu düşük akış rejiminin eseri olan ve çok az çakıl içeren ince taneli taşkın ovası sedimanlarından oluşmaktadır.

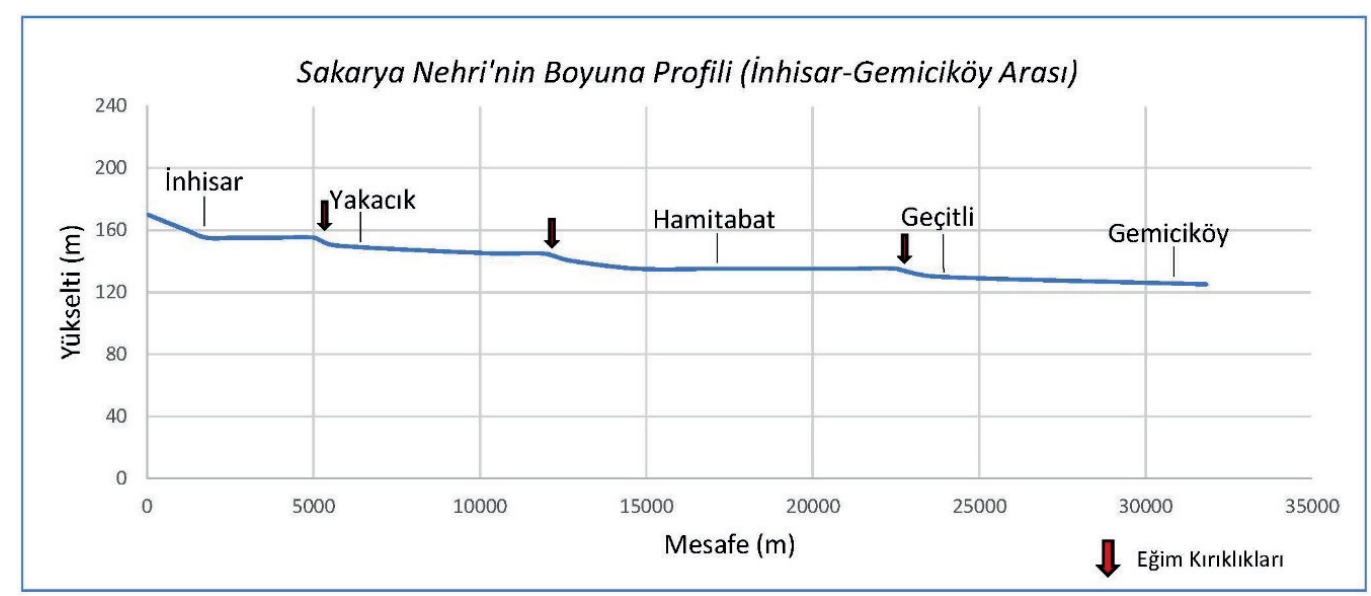

Şekil 11: Sakarya Nehri yatağı boyunca alınan boyuna profilde Kuvaterner yaşlı alüvyal birimler içerisinde gözlemiş olduğumuz eğim kırıklıkları, araştırma sahasındaki tektonik aktiviteye işaret etmektedir.

Figure 11: In the longitudinal profile of the Sakarya River bed, the slope fractures observed in the Quaternary aged alluvial units shows the tectonic activity in the study area. 
Çalışma alanındaki seki sistemleri, bölgesel/lokal tektonik etkilerin ortaya konulmasında ve bölgenin jeomorfolojik gelişiminin aydınlatılmasında kullanılabilecek son derece önemli jeomorfolojik ve sedimantolojik veriler sunmaktadır. $\mathrm{Bu}$ verilerin, seki dolgularının uygun yerlerinden yapılacak radyometrik tarihlendirmelerle desteklenmesi gerekmektedir. Sonuç olarak, yapmayı planladığımız bu tarihlendirmeler, hem Orta Sakarya vadisindeki seki sistemlerinin jeokronolojik bir çerçeveye oturtulmasını sağlayacak hem de Erturaç vd. (2019a)'nin Sakarya Nehri'nin aşağı çığırındaki seki sistemlerinde yapmış oldukları çalışmayı destekleyecektir.

Hakem Değerlendirmesi: Dıș bağımsız.

Çıkar Çatışması: Yazarlar çıkar çatışması bildirmemiştir.

Finansal Destek: Yazarlar bu çalışma için finansal destek almadığını beyan etmiştir.

Peer-review: Externally peer-reviewed.

Conflict of Interest: The authors have no conflict of interest to declare.

Grant Support: The authors declared that this study has received no financial support.

\section{KAYNAKÇA/REFERENCES}

Akkan, E. (1970). Kizılırmak vadisinin jeomorfolojisi. Ankara Üniversitesi, DTCF yayın No: 191, Ankara.

Avşin, N., Vandenberghe, J., Balen, V. R., Kıyak, N. G., Öztürk, T. (2019). Tectonic and climatic controls on Quaternary fluvial processes and river terrace formation in a Mediterranean setting, the Göksu River, southern Turkey. Quaternary Research, 91(2), 533547. https://doi.org/10.1017/qua.2018.129

Berndt, C., Yıldırım, C., Çiner, A., Strecker, M. R., Ertunç, G., Sarıkaya, M. A., Özcan, O., Öztürk, T., \& Kıyak, N. G. (2018). Quaternary uplift of the northern margin of the Central Anatolian Plateau: New OSL dates of fluvial and delta-terrace deposits of the Kiz1lirmak River, Black Sea coast, Turkey. Quaternary Science Reviews, 201, 446-469. https://doi.org/10.1016/j.quascirev.2018.10.029

Bilgin, T. (1980). Orta Sakarya platolarında yapı satıhları ve drenaj. TBTAK projesi, proje No: TBAG275, S.302, Ankara.

Bridgland, D. R., Demir, T., Seyrek, A., Pringle, M., Westaway, R., Beck, A. R., Rowbotham, G., \& Yurtmen, S. (2007). Dating Quaternary volcanism and incision by the River Tigris at Diyarbakır, southeast Turkey. Journal of Quaternary Science, 22(4), 387-393. https://doi: 10.1002/jqs.1074

Bridgland, D. R., Westaway, R., Romieh, M. A., Candy, I., Daoud, M., Demir, T., Galiatsatos, N., Schreve, D. C., Seyrek, A., Shaw, A. D., White, T. S., \& Whittaker, J. (2012). The River Orontes in Syria and Turkey: Downstream variation of fluvial archives in different crustal blocks. Geomorphology, 165-166, Pp. 25-49. doi:10.1016/j. geomorph.2012.01.011
Çiner, A., Doğan, U., Yıldırım, C., Akçar, N., Ivy-Ochs, S., Alfimov, V., Kubik, P. W., \& Schlüchter, C. (2015). Quaternary uplift rates of the Central Anatolian Plateau, Turkey: Insights from cosmogenic isochron-burial nuclide dating of the Kizllirmak River terraces. Quaternary Science Reviews, 107, 81-97. https://doi.org/10.1016/j. quascirev.2014.10.007

Doğan, U. (2011). Climate-controlled river terrace formation in the Kizilırmak Valley, Cappadocia section, Turkey: Inferred from $\mathrm{Ar}-\mathrm{Ar}$ dating of Quaternary basalts and terraces stratigraphy. Geomorphology, 126(1), 66-81. doi.org/10.1016/j.geomorph.2010.10.028

Doğan, U., Y1lmaz, E., Koçyiğit, A. (2019). Geomorphological evolutionary history of the Melendiz River, Cappadocia, Turkey. Mediterranean Geoscience Reviews, 1(2), 203-222. https://doi. org/10.1007/S42990-019-00012-6

Erol, O. (1973). Ankara şehri çevresinin jeomorfolojik ana birimleri. Ankara Üniversitesi DTCF, yay. No: 240, Ankara.

Erturaç, M. K. ve Kıyak, N. G. (2017). Yeşilırmak taraçalarında (Orta Kuzey Anadolu) geç Pleyistosen iklim değişiklikleri ve düşey yönlü deformasyona akarsu cevabının araştırılması. Türkiye Jeoloji Bülteni, 60, 615-663. Ankara. https://doi.org/10.25288/tjb.370625

Erturaç, M. K., Selçuk, A. S., Şahiner, E., Gürbüz, A., Okur, H. (2019a). Chronology of the Sakarya River terraces: Fluvial response to climate change, tectonic uplift and to the Black Sea level changes. International Union For Quaternary Research, 25-31 July 2019, Dublin. Erişim adresi: http://www.inqua2019.org/

Erturaç, M. K., Şahiner, E., Zabcı, C., Okur, H., Polymeris, G. S., Meriç, N., İkiel, C. (2019b). Fluvial response to rising levels of the Black Sea and to climate changes during the Holocene, Luminescence geochronology of the Sakarya terraces. The Holocene, 1-12. https:// doi.org/10.1177/0959683619831428

İlgüz, N. (1940). Ankara sekileri. Ziraat Vekaleti Yüksek Ziraat Enstitüsü Çalışmaları, S:104, Ankara.

İnandık, H. (1955). Morfolojide taraçalar meselesi. Türk Coğrafya Dergisi, S. 13-14. Ankara. Erişim adresi: https://dergipark.org.tr/tr/ $\mathrm{pub} / \mathrm{tcd} /$ issue $/ 21269 / 228358$

Karadoğan, S. ve Kuzucuoğlu, C. (2017). Diyarbakır Hevsel Bahçeleri ve Dicle Nehri: Arazi değişimlerinin jeomorfolojik kayıtları. Türkiye Jeoloji Bülteni, (60), S.1, s. 63-76. Ankara. Erişim adresi: https://www.jmo.org.tr/

Maddy, D., Veldkamp, A., Demir, T., Gorp, W. V., Wijbrans, J. R., Hinsbergen, D. J. J., Dekkers, M. J., Schreve, D., Schoorl, J. M., Scaife, R., Stemerdink, C., Schriek, T., Bridgland, D.R., \& Aytaç, A.S. (2016). The Gediz River fluvial archive: A benchmark for Quaternary research in western Anatolia. Quaternary Science Reviews, 166, 289 306. https://doi.org/10.1016/j.quascirev.2016.07.031

Maddy, D., Veldkamp, A., Demir, T., Aytaç, A.S., Schoorl, J. M., Scaife, R., Boomer, I., Stemerdink, C., Schriek, T., Aksay, S., \& Lievens, C. (2020). Early Pleistocene river terraces of the Gediz River, Turkey: The role of faulting, fracturing, volcanism and travertines in their genesis. Geomorphology, 358.https://doi.org/10.1016/j.geomorph.2020.107102 
McClain, K., Yıldırım, C., Çiner, A., Şahin, S., Sarıkaya, M. A., Özcan, O., Kıyak, N. G., Öztürk, T. (2019). Fluvial response to tectonic deformation in the western flank of the Turkish Central Pontides; Inferences from OSL-Ages. 72nd Geological Congress of Turkey With International Participation, 29 January-01 February 2019. Ankara. Erişim adresi: https://www.jmo.org.tr/etkinlikler/kurultay/ index.php?etkinlikkod $=136$

Okay, A. (1989). Tectonic evolution of the Tethyan Region. Şengör, A.M.C. (Ed.), Tectonic Units And Sutures İn The Pontides, Northern Turkey. Kluwer Academic Publishers, (pp. 109-116). Springer, Dordrecht. https://doi.org/10.1007/978-94-009-2253-2

Pfannenstiel, M. (1941). Ankara'nın Diluvyal moloz sekileri ve Avrupa'nın Quärter kronolojisine göre tasnifleri. Yüksek Ziraat Enstitüsü Çalışmaları, S:120, Ankara.

Schumm, S., Dumont, J., \& Holbrook, J. M. (2000). Active tectonics and alluvial rivers, Cambridge University Press, Cambridge.
Şahiner, E., Erturaç, M. K., Polymeris, G. S., \& Meriç, N. (2018). Methodological studies on integration time interval's seletion for the luminescence ages using quartz and feldspar minerals; Sediments collected from Sakarya, Turkey. Radiation Measurements, 120, 163 169, https://doi.org/10.1016/J.Radmeas.2018.06.024

Uncu, L. ve Karakoca, E. (2019). Evaluating the geomorphological features and geotourism potentials of Harmankaya Canyon (Bilecik, Turkey). Journal of Tourism and Hospitality Management, 7, No.1, pp.1-14. doi.org/10.17265/2328-2169/2019.01.001

Vandenberghe, J. (2002). The relation between climate and river processes, landforms and deposits during the Quaternary. Quaternary International, 91, 17-23. https://doi.org/10.1016/ S1040-6182(01)00098-2

Westaway, R., Pringle, M., Yurtmen, S., Demir, T., Bridgland, D., Rowbotham, G., \& Maddy, D. (2003). Pliocene and Quaternary regional uplift in western Turkey revealed by long-term river terrace sequences. Current Science, 84(8), 1090-1101. Erişim adresi: https://www.currentscience.ac.in/ 
